\title{
Intrathecal Baclofen Therapy in Russia: National Register of Spastic States
}

\author{
DOI: 10.17691/stm2018.10.4.19 \\ Received August 10, 2018
}

\begin{abstract}
I.N. Morozov, MD, DSc, Head of the Center of Neurorehabilitation of Patients with Vertebral and Cerebrospinal Pathology';

K.V. Slavin, Professor, Head of Stereotaxic and Functional Neurosurgery Department ${ }^{2}$

${ }^{1}$ Privolzhsky Research Medical University, 10/1 Minin and Pozharsky Square, Nizhny Novgorod, 603005, Russia;

2University of Illinois at Chicago, 1200 W Harrison St., Chicago, IL 60607, USA
\end{abstract}

Patients with severe muscle spasticity are still one of the most complicated and resistant to therapies groups of neurorehabilitation patients. During the last several years of its application intrathecal baclofen therapy has become an effective method of treating spasticity which is resistant to other therapies and has a negative impact on patients' quality of life. Despite its wide acknowledgement some clarification is needed to confirm the actual need in this method for the current clinical practice as well as the development of general recommendations for treating these patients.

There was a protocol of National Prospective Register for treating spastic states with intrathecal baclofen therapy in the Russian Federation developed and there was an available electronic source created, which allows to organize the data on the therapy of patients with spasticity, analyze the therapy schemes used, evaluate the therapy outcomes and frequency of adverse events in a wide population.

Key words: muscle spasticity; intrathecal baclofen therapy; register of spastic states treatment.

\section{Introduction}

Spasticity as one of the components of upper motor neuron damage syndrome, which is characterized by changes on muscular tension that is dependent on the rate of spreading and repeated involuntary contractions of skeleton muscles (spasms) [1]. Muscle rigidity hinders the patient's movements, involuntary twitching of limbs and the body in impairs mobility, sleep, and ability for self-care of such patients. Disabling high muscle tension in $40-68 \%$ of cases is observed in patients who had spinal injury and in $65-84 \%$ in patients with multiple sclerosis [1]. Severe muscular spasticity occurs in $20-25 \%$ of post-stroke patients [2-6], the frequency of severe muscular spasticity after a serious craniocerebral injury reaches $85 \%$ [7-10]. The issue of muscular hypertension in children is significant. Spastic pareses develop in $65-98 \%$ of children with cerebral palsy [1113]. Prevalence of pathologically changed muscular tension in patients after myelitis, spinal stroke, and myeloischemia is less studied.

A traditional treatment of spasticity presupposes the use of therapeutic exercises, massage, reflex therapy, physiotherapy, injection of botulinum toxin into the motor points of spastically contracted muscles. Botulinum toxin therapy is especially effective for equinovarus foot deformity caused by spasticity of the posterior group of calf muscles and for high tension of flexor muscles of wrists and fingers, i.e. for localized focal spasticity [2, 14, 15].

Surgical operations to reduce spasticity can be conducted at four levels: on the brain (electrocoagulation of the pale globe, ventral intermediate nucleus of thalamus or cerebellum), on the spine (selective posterior rhizotomy), on the peripheral nerves (dissection of peripheral nerves), and on the muscles or their tendons. Before the 1980s the main method of treatment of severe spastic syndromes involved destructive neurosurgical interferences - selective posterior rhizotomy and DREZ-tomy. Their effect was based on the destruction of a stretch reflex chain resulting in reflex decrease in spasticity. Despite their high effectiveness, these interferences have one considerable disadvantage: in some cases, patients can develop uncontrolled muscular weakness that impairs locomotor functions in those patients who use muscular tension for walking.

The most widely used medication for spasticity treatment since the moment of its first practical use in 1971 has been baclofen [16]. However at ingestion it badly penetrates blood-brain barrier, therefore high concentration of this medication in blood is required in order to reach its satisfactory level in the cerebrospinal fluid. Furthermore, administration of muscle relaxants 
that require high therapeutic dosages inevitably leads to development of side-effects $[8,9]$.

The first intrathecal administration of baclofen was reported in 1984. The therapeutic concentration of the medication in the cerebrospinal fluid was reached at the dosage of 400-1000 times less compared to oral administration. Since then intrathecal therapy with baclofen (ITB) with the use of reservoirs implanted in patients (programmed medical pumps) has been an effective method of treatment for some non-focal spastic syndromes, since 1993 - of cerebral palsy, since 2000 - of hyperkinesis and secondary dystonia of different etiology impairing the life quality of patients resistant to traditional surgical and pharmaceutical treatment [1, 3, 5, 17, 18]. Since 2010 ITB has been used in Russia.

The pump operation is connected with dosed supply of baclofen into the subarachnoid space of the spinal cord. Baclofen is an antagonist of GABA-ergic receptors of alpha-motoneurons of the spinal cord. The medication affects the receptors, suppresses tonic activity of motoneurons and leads to the reduction of pathological muscular tension. Due to this mechanism of action chronic intrathecal therapy influences not only the spastic component of muscular tension, which is realized via a stretch reflex arc, but also the rigid component, which is realized impacting the descending tracts of the extrapyramidal system.

According to the information of Medtronic Evidence Compendium, in the USA in 2016 there were 649 thousand patients with spasticity caused by cerebral palsy registered; 268 thousand patients - with multiple sclerosis, at that drug-resistant forms were registered in 50 and $38 \%$ of cases, respectively; in 172 thousand examined patients spasticity was developed as a result of a spinal injury and in 1.5 million patients it was caused by a cerebral stroke. In 83 thousand spinal and 438 thousand post-stroke patients an increased disabling muscular tension was resistant to medication therapy, kinesitherapy and physiotherapy $[19,20]$.

Currently, there are more than 250 thousand disabled patients with spinal injuries in Russia including 100 thousand patients with muscular spasticity caused by traumatic damage of the spinal cord and one third of them had muscular tension resistant to the traditional therapy [21, 22]. More than 400 thousand strokes are annually registered in the Russian Federation. The main post-stroke defect that disables patients is spastic hemiparesis (up to $80 \%$ of cases) [21, 22].

There are no reliable data on prevalence of drugresistant spasticity impairing the quality of life of patients with demyelinating diseases, cerebral palsy and cerebral pathology in Russia. However, considering a significant population of these patients, one can assume that a real need in ITB is much higher than the number of baclofen pumps implanted annually. Over 280 thousand pumps were implanted during thirty years of the global experience in this therapy, whereas in
Russian according to some clinical data - only about 500 devices.

Further development of ITB in Russian and provision of technology intensive medical assistance requires establishment of a system allowing adequate selection of patients with the account to indications for therapy application, correct choice of a daily dosage and administration mode, effective long-term follow-up and patients' training after the pump implantation. But at present there are no clinical data on the real situation of ITB application in Russia. Domestic publications on this topic are of occasional character $[1,23]$.

The authors consider obtaining data from the Russian centers that use ITB in patients with spastic states, systematization of these findings, analysis and evaluation of treatment outcomes and adverse events with further practical recommendations an objective for establishment of the National Prospective Register providing for assessment of the situation with application of this method in Russia.

\section{Materials and Methods}

The authors considered necessary to investigate the following information to study the situation with intrathecal baclofen therapy in Russia:

indication for a pump implantation and compliance with therapy prescribed;

adequacy of the previous muscle relaxants treatment;

frequency and timeliness of pump refilling and patients' compliance with the regular refilling;

correct pump programming.

The authors selected the following most widespread and sensitive methods of studying to evaluate ITB effectiveness:

muscular spasticity (Ashworth scale);

frequency of muscular spasms (muscular spasms scale);

explicitness of pain syndrome caused by spasticity (visual analogue scale);

life impairment (modified Rankine scale);

patients' quality of life (Karnofsky index).

In order to evaluate safety of the therapy performed the authors arranged adverse events related to pharmacokinetics and pharmacodynamics of baclofen and caused by the pump administration procedure and/or device. The obtained findings provided for identification of the causes and frequency of complications of baclofen therapy.

In Russia patients with intrathecal therapy are treated in 20 centers, children are treated in 7 of them. The selection of criteria for the Register to be developed was based on the results of the staff questionnaire survey in these centers.

The Register was suggested to include all the patients (adults and children) with an implanted pump for intrathecal administration of baclofen regardless of the therapy duration (at the stage of pump implantation, re- 
implantation after the end of the pump life time, refilling and/or reprogramming of the pump) according to various indications that conform to the inclusion criteria.

The following inclusion criteria were selected for the Register:

1) a signed informed consent for inclusion into the Register (in case of children the form is to be signed by parents or guardians);

2) availability of an implanted pump for intrathecal administration of baclofen.

The criterion for non-inclusion into the Register was a refusal to sign the informed consent form.

Criteria for exclusion from the Register:

1) a patient's voluntary refusal to be further included into the Register;

2) a need for the pump explantation;

3) a patient's death.

\section{Results}

To achieve the set objective the authors solved the following two tasks during our investigation:

1. The authors developed a protocol of the National Prospective Register of treatment of spastic stated with intrathecal baclofen therapy in the Russian Federation. This Register arranges the issues related to treatment of spastic states with a pump therapy in real clinical practice, consistently describes every visit, therapy parameters, tools for evaluation of the therapy effectiveness, adverse events or complications and the results that are registered in a patient medical record after each visit.

2. The authors established an automated information system (AIS). The system is available on a dedicated internet website and can be accessed from a work place of each center employee. Registration on the website gives access to the data uploaded into AIS by any center. The authors made an individual record file for each patient to be filled after each visit (inclusion, follow-ups, final visit), which allows to collect information on demographic (inclusion visit) and clinical laboratory findings, on effectiveness of therapy (scales of evaluating spasticity, pain, life quality), on pump parameters and adverse events in a correct, quantitative, ranked and unified manner. The system automatically generates monthly reports that can help assess correctness of the uploaded information, find the missing data in each center participating in the Register, make intermediate reports on any required parameters (epidemiological effect, therapy effectiveness, and adverse effects), automatically edit and verify the studied data on a regular basis.

While working on the Register the authors obtained enough information to analyze the existent situation and make adequate decisions.

The Register is arranged as a prospective study, i.e. all the investigations occur after getting clinical outcomes. According to the first results received $2 / 3$ of

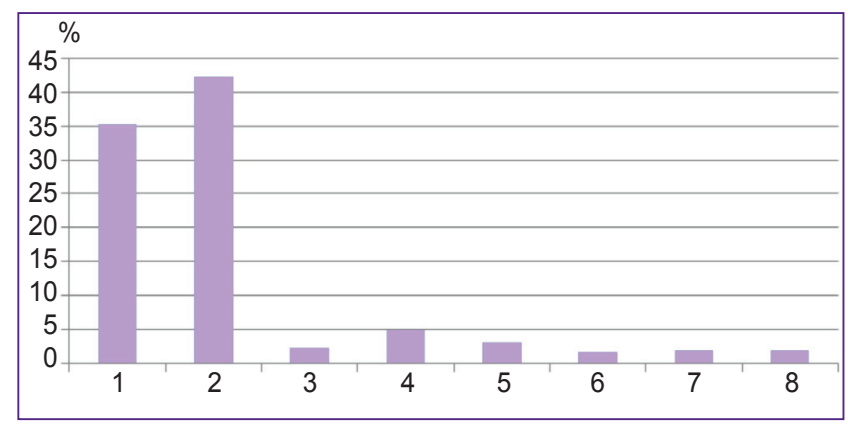

Reasons for spasticity in patients who underwent ITB according to the Register data:

1 - cerebral palsy; 2 - spinal injury; 3 - brain injury; 4 multiple sclerosis; 5 - myeloischemia; 6 - myelitis; 7 - acute cerebrovascular accident; 8 - Marie-Strumpell disease

patients with ITB are males. The average age of adults from the moment of inclusion into the Register was 37 $[24 ; 65]$ years.

The most frequent reasons for spasticity are the consequences of a spinal injury and cerebral palsy (see the Figure). The examined patients had a reliable decrease in spasticity level by 1 point according to Ashworth scale (the patients with multiple sclerosis did not have any reliable decrease in tension).

The most frequent adverse events related to ITB administration include the catheter issues (migration, patency problems) - in $2.5 \%$ of cases and infection of a pump pocket in $3.8 \%$ of cases, the complications caused by pharmacokinetics and pharmacodynamics of the medication included diplopia and dizziness $(5 \%$ of patients).

\section{Conclusion}

Muscular spasticity significantly impairs the life quality of patients suffering the consequences of injuries and diseases of the nervous system, the problem of its treatment is still unsolved. Nevertheless, in the last years intrathecal baclofen therapy has become the most effective method to treat the spasticity resistant to other therapies and impairing patient's life quality in Russia.

The authors established the National Prospective Register of intrathecal baclofen treatment of spastic states in the Russian Federation, developed the protocol and an accessible website that can help organize the therapy of patients in the country, control the use of the intrathecal baclofen therapy method, and evaluate effectiveness of the treatment conducted.

The data from the Register will allow giving recommendations to patients: to specify the patients selection criteria, analyze the obtained results, outcomes and complications, specify the procedure details and the rules of the patients follow up.

Funding. The work was not funded. 
Conflicts of interest. The authors declare no conflicts of interest.

\section{References}

1. Morozov I.N., Ushakov A.I. ITB therapy of spasticity. Poliklinika 2017; 4-2: 38-40.

2. Parfenov V.A. Post-stroke spasticity and its treatment. Russkiy meditsinskiy zhurnal 2006; 9: 689.

3. Francisco G.E., Boake C. Improvement in walking speed in poststroke spastic hemiplegia after intrathecal baclofen therapy: a preliminary study. Arch Phys Med Rehabil 2003;84(8):1194-1199, https://doi.org/10.1016/s0003-9993(03) 00134-5.

4. Ivanhoe C.B., Francisco G.E., McGuire J.R., Subramanian T., Grissom S.P. Intrathecal baclofen management of poststroke spastic hypertonia: implications for function and quality of life. Arch Phys Med Rehabil 2006; 87(11): 1509-1515, https://doi.org/10.1016/j.apmr.2006.08.323.

5. Meythaler J.M., Guin-Renfroe S., Brunner R.C., Hadley M.N., Francisco G.E. Intrathecal baclofen for spastic hypertonia from stroke. Stroke 2001; 32(9): 2099-2109, https:// doi.org/10.1161/hs0901.095682.

6. Schiess M.C., Oh I.J., Stimming E.F., Lucke J., Acosta F., Fisher S., Simpson R.K. Prospective 12-month study of intrathecal baclofen therapy for poststroke spastic upper and lower extremity motor control and functional improvement. Neuromodulation 2011; 14(1): 38-45, https://doi.org/10.1111/ j.1525-1403.2010.00308.x.

7. Becker R., Alberti O., Bauer B.L. Continuous intrathecal baclofen infusion in severe spasticity after traumatic or hypoxic brain injury. J Neurol 1997; 244(3): 160-166, https://doi. org/10.1007/s004150050067.

8. Meythaler J.M., DeVivo M.J., Hadley M. Prospective study on the use of bolus intrathecal baclofen for spastic hypertonia due to acquired brain injury. Arch Phys Med Rehabil 1996; 77(5): 461-466, https://doi.org/10.1016/s00039993(96)90034-9.

9. Meythaler J.M., Guin-Renfroe S., Grabb P., Hadley M.N. Long-term continuously infused intrathecal baclofen for spastic-dystonic hypertonia in traumatic brain injury: 1-year experience. Arch Phys Med Rehabil 1999; 80(1): 13-19, https://doi.org/10.1016/s0003-9993(99)90301-5.

10. Ordia J.I., Fischer E., Adamski E., Spatz E.L. Continuous intrathecal baclofen infusion delivered by a programmable pump for the treatment of severe spasticity following traumatic brain injury. Neuromodulation 2002; 5(2): 103-107, https://doi.org/10.1046/j.1525-1403.2002.02015.x.

11. Albright A.L., Cervi A., Singletary J. Intrathecal baclofen for spasticity in cerebral palsy. JAMA 1991; 265(11): 14181422, https:/doi.org/10.1001/jama.1991.03460110084029.

12. Butler C. Campbell S. Evidence of the effects of intrathecal baclofen for spastic and dystonic cerebral palsy. AACPDM Treatment Outcomes Committee Review Panel. Dev Med Child Neurol 2000; 42(9): 634-645, https://doi. org/10.1017/s0012162200001183.
13. Gilmartin R., Bruce D., Storrs B.B., Abbott R. Krach L., Ward J., Bloom K., Brooks W.H., Johnson D.L., Madsen J.R., McLaughlin J.F., Nadell J. Intrathecal baclofen for management of spastic cerebral palsy: multicenter trial. J Child Neurol 2000; 15(2): 71-77, https://doi.org/10.1177/08 8307380001500201.

14. Simpson D.M., Gracies J.M., Graham H.K., Miyasaki J.M., Naumann M., Russman B., Simpson L.L., So Y. Assessment: botulinum neurotoxin for the treatment of spasticity (an evidence-based review): report of the Therapeutics and Technology Assessment Subcommittee of the American Academy of Neurology. Neurology 2008, 70(19): 1691-1698, https://doi.org/10.1212/01. wnl.0000311391.00944.c4.

15. Lindsay C., Kouzouna A., Simcox C., Pandyan A.D. Pharmacological interventions other than botulinum toxin for spasticity after stroke. Cochrane Database Syst Rev 2016; 10 : CD010362, https://doi.org/10.1002/14651858.cd010362.pub2.

16. Jones R.F., Lance J.W. Bacloffen (Lioresal) in the long-term management of spasticity. Med J Aust 1976; 1(18): 654-657.

17. Gwartz B.L. Intrathecal baclofen for spasticity caused by thrombotic stroke. Am J Phys Med Rehabil 2001; 80(5): 383-387, https://doi.org/10.1097/00002060-200105000-00014.

18. Rémy-Néris O., Tiffreau V., Bouilland S., Bussel B. Intrathecal baclofen in subjects with spastic hemiplegia: assessment of the antispastic effect during gait. Arch Phys Med Rehabil 2003; 84(5): 643-650, https://doi.org/10.1016/ s0003-9993(02)04906-7.

19. Medtronic ITB evidence compendium. Minneapolis; USA; 2017.

20. Creamer M., Cloud G., Kossmehl P., Yochelson M., Francisco G.E., Ward A.B., Wissel J., Zampolini M., Abouihia A., Berthuy N., Calabrese A., Loven M., Saltuari L. Intrathecal baclofen therapy versus conventional medical management for severe poststroke spasticity: results from a multicentre, randomised, controlled, open-label trial (SISTERS). J Neurol Neurosurg Psychiatry 2018; 89(6): 642650, https://doi.org/10.1136/jnnp-2017-317021.

21. Vedenie bol'nykh s posledstviyami pozvonochnospinnomozgovoy travmy na vtorom i tret'em etapakh meditsinskoy i mediko-sotsial'noy reabilitatsii. Klinicheskie rekomendatsii [Management of patients with consequences of a spinal injury at the second and third stages of medical and medical-social rehabilitation. Clinical recommendations]. Pod red. Ivanovoy G.E., Volovets S.A., Morozova I.N. [Ivanova G.E., Volovets S.A., Morozov I.N. (editors)]. Moscow; 2017; 320 p.

22. Morozov I.N. Pozvonochno-spinnomozgovaya travma: vosstanovitel'noe lechenie $v$ promezhutochnom i pozdnem periodakh. Avtoref. dis. ... dokt. med. nauk [Spinal injury: rehabilitation treatment in the intermediate and late periods. DSc Thesis]. Nizhny Novgorod; 2011.

23. Bikmullin T.A., Levin M.S., Bariev E.R., Khakimova F.N. Features of treatment after of baklofen pump implantation. Prakticheskaya meditsina 2017; 1: 96-100. 